\title{
AUTUMN AND SPRING CONTROL OF BLACK CHERRY APHID ON SWEET CHERRY IN CENTRAL OTAGO
}

\author{
G.F. McLAREN and J.A. FRASER
}

The Horticulture and Food Research Institute of New Zealand, Clyde Research Centre, R.D. 1 Alexandra, Central Otago, New Zealand

Corresponding author: gmclaren@hortresearch.co.nz.

\begin{abstract}
Black cherry aphid Myzus cerasi has the potential to cause major damage to both the shoots and fruit of sweet cherries. It has traditionally been treated with insecticides during the growing season, from early spring until close to harvest. An investigation into the time of arrival of females followed by males in autumn and egg hatch in spring in Central Otago showed that there was potential to achieve some control before flowering by treating either in autumn or spring. The trials identified options for use under organic (mineral oil, canola oil or pyrethrum) or integrated fruit production systems (mineral oil or pirimicarb) with carefully timed treatments. Aphid numbers in spring (assessed in late October) were significantly reduced by treating in either late April of the previous autumn or in late August at the end of egg hatch. Further work is needed to develop fully effective control programmes using combinations of autumn and spring treatments.
\end{abstract}

Keywords: black cherry aphid, Myzus cerasi, summerfruit, stonefruit, insecticidal control.

\section{INTRODUCTION}

Black cherry aphid Myzus cerasi (Fabricius) (BCA), an introduced pest of both sweet cherry Prunus avium L. and sour cherry Prunus cerasus L., is particularly important in commercial sweet cherry orchards in New Zealand. If it is not controlled, it causes leaf curling and suppression of growth in spring and summer, while sticky exudate on the fruit can render the crop unsaleable (McLaren 1999). The timing of the control programme for BCA has changed little from the "winter oil during the dormant season or nicotine sulphate or organic phosphate [organophosphate] sprays during early spring" reported by Kemp (1955). The current programme uses slightly different insecticides and timing, with treatment delayed until bud movement when mineral oil is applied with pirimicarb (a carbamate) or chlorpyrifos (an organophosphate). However, this single application is sometimes not fully effective and diazinon (an organophosphate) is often applied up to 14 days before harvest. However, the future of diazinon is uncertain for fruit being exported to markets where organophosphates are now banned. As there are no immediate prospects for a diazinon replacement, it would be helpful to eliminate the need for its use by achieving effective control before flowering. Cherry is the most rapidly expanding of the summerfruit (stonefruit) crops in New Zealand with $90 \%$ of the 600 tonnes of export fruit being sold in Asia. Future export markets will depend on achieving a high level of BCA control before flowering.

BCA has a complex annual cycle, moving from its primary hosts, sweet and sour cherry, to secondary hosts, mainly weeds, in summer (Blackman \& Eastop 1985). In Canterbury, Farrell \& Stufkens (1988) reported that winged forms (alatae) of BCA occur in spring (October to December) and autumn (March - May), but the time of oviposition by the wingless sexual females (sexuales) in autumn was not known. The timing of egg hatch during August in Central Otago had been established (McLaren 1999) but the most effective time to apply oils in spring has not been determined. 
The initial aim of the current research programme was to identify the time when BCA returns to cherry, its primary host, as well as establishing the time of oviposition in autumn and egg hatch in spring. This information was then used to plan trials to test insecticides for use against BCA in both integrated fruit production (IFP) and organic orchards.

\section{METHODS}

All population monitoring and experimental trials were conducted at HortResearch's Clyde Research Centre in Central Otago.

\section{Phenology}

From March to May 2001, winged BCA females and males were collected continuously from the air $1.2 \mathrm{~m}$ above the ground using a suction trap (Johnson \& Taylor 1955) situated in open grassland. Catches were inspected three times per week and identified using the descriptions of Cottier (1953).

The shiny black eggs of BCA were recorded on unsprayed cherry trees by inspecting the dormant buds with a hand lens (x10) in July 1980, 1999, 2000 and 2001. Sites where eggs were found were tagged; the same eggs $(n=30-40$ eggs on 6-10 trees/year) were inspected twice per week on unsprayed sweet cherries until no further hatches had been recorded and infertile (collapsed) eggs could be identified.

The development of populations of three aphid species was recorded on their respective Prunus spp. host plants growing in adjoining blocks in 2000-01; BCA was recorded on cherry, green peach aphid (GPA), Myzus persicae (Sulzer), on nectarine and leafcurl plum aphid (LCPA), Brachycaudus helichrysi (Kaltenbach), on Japanese plum. The total number of infested (curled) tips per tree was recorded on all the trees $(\mathrm{n}=110$ plum, 110 nectarine and 88 cherry trees) in each of the unsprayed blocks over the growing season at 2-4 week intervals. On each occasion, a sample of 40-50 leaves with symptoms of aphid feeding was checked microscopically for the presence of winged and wingless aphids; numbers of aphids per leaf were recorded, together with the number of biological controls agents.

\section{Autumn trials to control BCA}

A preliminary trial (Trial 1), conducted on eight-year old cherry trees (cv. Noir de Guben) planted at $5 \times 4.5 \mathrm{~m}$ spacing, consisted of a randomised plot design with four replicates of single-tree plots with guard trees between. The first two treatments were pyrethrum (Yates' Pyrethrum $500 \mathrm{ml} / 100$ litres) applied with a handgun at 7 litres/tree on 20 March or 3 April 2000. The third treatment was kaolin (Surround ${ }^{\mathrm{TM}}$ ) applied at $5000 \mathrm{~g} / 100$ litres with an airblast sprayer at 200 litres/ha on 17 March 2000. The number of infested tips per tree was assessed on 30 October 2000, which was before winged forms appeared.

A second trial compared early (9 and 24 April 2001) and late (24 April and 9 May 2001) applications of four insecticides in autumn 2001. The treatments included kaolin (Surround ${ }^{\mathrm{TM}}$ at $5000 \mathrm{~g} / 100$ litres), garlic and pyrethrum (Betta-Crop Organics with $12 \mathrm{~g} /$ /itre pyrethrum, $500 \mathrm{ml} / 100$ litres), canola oil (South Oils, 2 litres/100 litres) and pirimicarb (Pirimor ${ }^{\mathrm{TM}}$, $25 \mathrm{~g} / 100$ litres). The trial design consisted of a randomised block with four replicates of five trees per plot. Each replicate consisted of a different cherry cultivar, Stella, Summit, Lapins or Sweetheart, planted at $4.5 \times 3 \mathrm{~m}$ spacing. All treatments were applied with a handgun and experimental sprayer applying 6 litres/tree. No further insecticides were applied until the number of infested tips present on each tree was recorded on 31 October 2001.

\section{Spring trials to control BCA}

Trial 3 aimed to find the most effective time to prevent the start of the spring population and to determine if oil could control the active stages of BCA as well as the eggs. Mineral oil (2\%) was applied with an airblast sprayer at 2000 litres water/ha on either 13 August 1999 or 27 August 1999; other trees were left untreated. The trial was applied to a block of nine-year old cherries (cv. Noir de Guben) planted at 5 x $4.5 \mathrm{~m}$ spacing, using a randomised plot design with three replicates of six-tree plots. The number of infested tips per tree was recorded on every tree on 2 November 1999.

A second spring trial (Trial 4) compared three insecticides applied on 30 August 2000 with an untreated control on a block of 21-year old cherry trees (cv. Noir de Guben) planted at $6 \times 12 \mathrm{~m}$ spacing. The trial was carried out in a randomised plot design with 
four replicates of single-tree plots. Treatments were pyrethrum (Yates' Pyrethrum) $500 \mathrm{ml} / 100$ litres, canola oil (2 litres/100 litres) and kaolin (New Zealand China Clay, 20 litres/100 litres), and were applied with a handgun and experimental sprayer ( 8 litres/tree). The number of infested tips per tree was recorded on 31 October 2000. Statistical Analysis

The number of infested tips recorded per tree at the end of October or early November each year was analysed by analysis of variance using SOLO (Hintze 1989).

\section{RESULTS AND DISCUSSION}

Phenology

In spring the number of BCA populations (as measured by number of infested twigs) increased rapidly on cherry, as did LCPA on plum; the number of GPA-infested twigs increased more slowly on nectarine until late November. Winged individuals started to appear in mid November on all hosts but the final departure of BCA from cherry was later than that of GPA or LCPA from their respective hosts. A large number of populations of BCA continued on cherry into January, by which stage, GPA and LCPA had disappeared (Fig. 1). This delay in the departure of winged BCA resulted in heavy infestations on untreated cherries at harvest, with some trees having $100 \%$ infested tips.

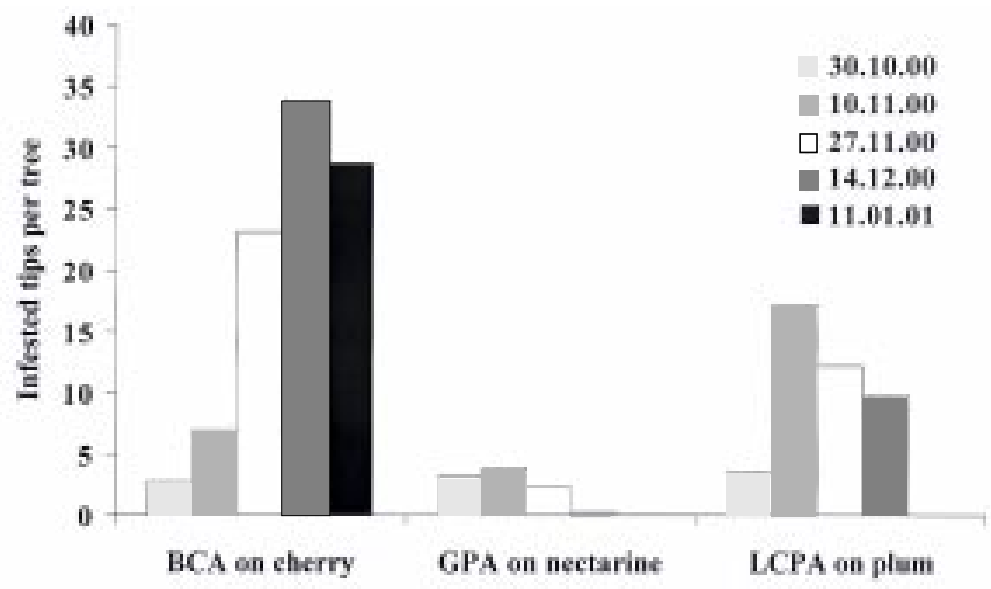

FIGURE 1: Number of aphid infested tips per tree over time (October 2000 to January 2001) on Japanese plum infested with Brachycaudus helichrysi (Kaltenbach) (LCPA), nectarine infested with Myzus perscicae (Sulzer) (GPA) and cherry infested with Myzus cerasi (F.) (BCA) sampled at Clyde Research Centre.

The first adult males were caught in the suction trap in late April, five weeks later than the appearance of winged females of the previous parthenogenetic generation (Fig. 2). This pattern of late development of the males has been recorded at Clyde over three years (G.F. McLaren, unpubl. data). Wingless (oviparae) females were observed ovipositing near flower buds during leaf fall, and some fell to the ground with the leaves. It remains unclear when oviposition ceases and if females can survive on the trees after leaf fall. Single eggs were found between dormant flower buds in late July and these started to hatch at the beginning of August (Fig. 3). Most had hatched by the end of August. Generations of parthenogenic females developed slowly through September and October, but numbers of aphids per leaf and infested shoots per tree increased rapidly 


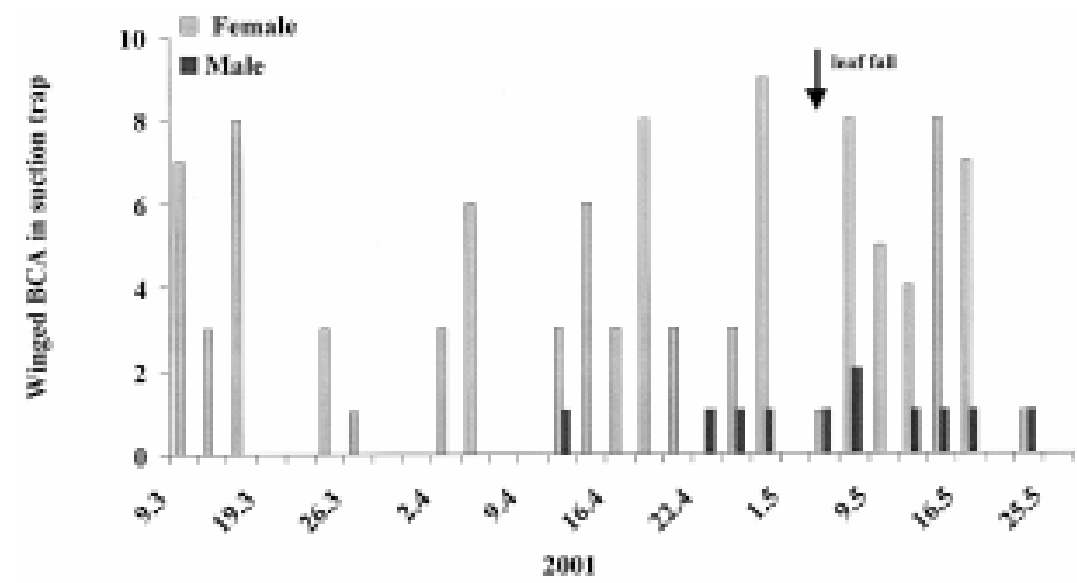

FIGURE 2: Numbers of winged females and males collected in a suction trap at Clyde Research Centre, March to May 2001.

in November (Fig. 4), when the first winged females appeared. Aphid numbers increased in November and December despite an increase in the numbers of biological control agents such as the coccinelids (mainly Coccinella spp.) which were the most common. The impact of the European earwig was difficult to assess due to its mobility and nocturnal habits. Although the abundance of coccinelids increased with that of the aphids, they (and other biological control agents) were unable to maintain numbers of BCA below acceptable levels before cherry harvest in December. In the absence of effective biological control, chemical intervention appears to be needed in the management of BCA on Central Otago cherry crops, as concluded earlier by Cottier (1953).

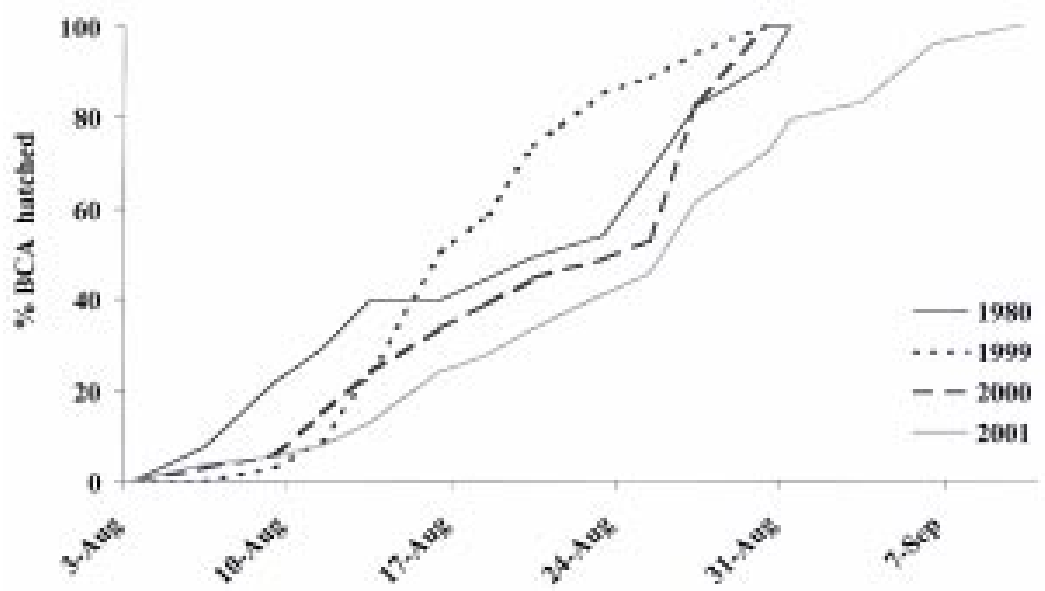

FIGURE 3: Cumulative percentage hatch of black cherry aphid eggs on cherry in spring over four years in Central Otago. 


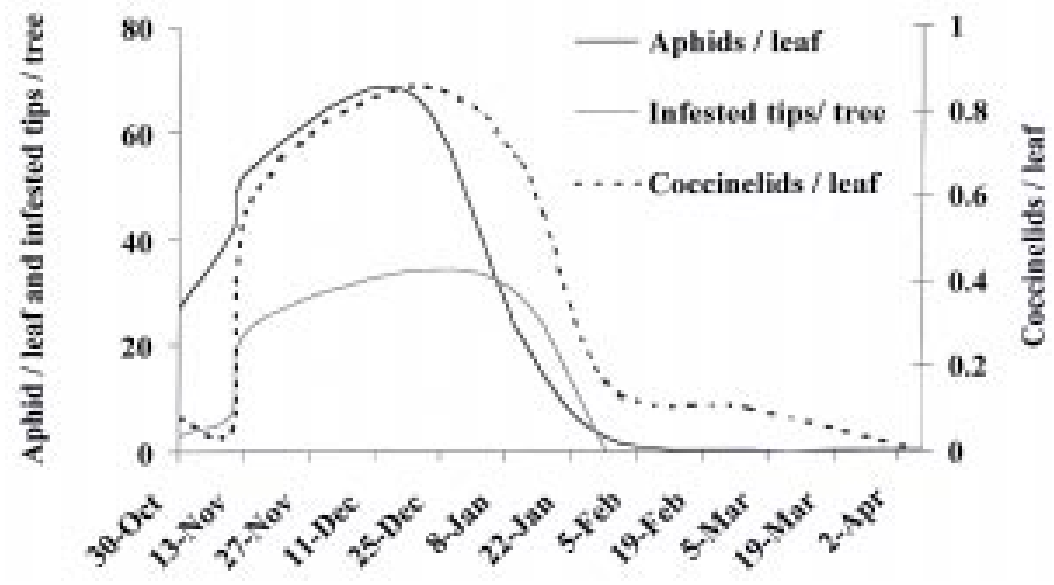

FIGURE 4: Mean number of black cherry aphids and Coccinelids per infested cherry leaf sampled at Clyde Research Centre over the 2000-01 growing season.

Autumn trials to control BCA

Trial 1 aimed to examine the possibility of controlling aphids in autumn. However, no difference $(\mathrm{P}>0.05)$ in the number of infested tips per tree was found between the three different insecticide treatments applied in autumn and the control (Table 1).

TABLE 1: Spring populations of black cherry aphid on cherry cv. Noir de Guben after applications of insecticide in autumn 2000.

\begin{tabular}{lccc}
\hline Treatment & Application date & Mean $( \pm S E M)$ & infested tips per tree \\
\hline Pyrethrum (Yates' pyrethrum) & 20 March & 5.5 & $(2.25)$ \\
Pyrethrum (Yates' pyrethrum) & 3 April & 8.0 & $(2.27)$ \\
Kaolin (Surround $^{\mathrm{TM}}$ ) & 17 March & 1.25 & $(0.75)$ \\
Untreated & & 5.0 & $(1.47)$ \\
& & $\mathrm{P}>0.05$ &
\end{tabular}

${ }^{1}$ Measured on 30 October 2000.

The late appearance of the males in the suction trap in autumn suggested that eggs were being laid later in the growing season. Consequently, in Trial 2, treatments were delayed until April and early May 2001 (Table 2). As no difference was found between the two application dates for each product or product combination, the data from both dates were combined for analysis. This showed that both garlic and pyrethrum and pirimicarb reduced aphid infestations the following spring but neither kaolin nor canola oil reduced infestation compared with the untreated. 
TABLE 2: Number of tips per tree $( \pm$ SEM) infested with black cherry aphids on 31 October 2001 after insecticides had been applied to cherry trees in the previous autumn.

\begin{tabular}{|c|c|c|c|}
\hline Treatment & $\begin{array}{c}\text { Application } \\
\text { dates } 2001\end{array}$ & $\begin{array}{l}\text { Mean infested tips } \\
\text { per tree (individual } \\
\text { treatment means) }\end{array}$ & $\begin{array}{c}\text { Mean infested tips } \\
\text { per tree per } \\
\text { chemical }\end{array}$ \\
\hline Kaolin & 9 and 24 April & $5.4(1.1) b^{1}$ & $5.0(0.7) \mathrm{b}$ \\
\hline Kaolin & 24 April and 9 May & $4.6(0.8) b$ & \\
\hline Garlic and pyrethrum & 9 and 24 April & $0.8(0.3) \mathrm{a}$ & $1.3(0.2) \mathrm{a}$ \\
\hline Garlic and pyrethrum & 24 April and 9 May & $1.6(0.4) \mathrm{a}$ & \\
\hline Canola oil & 9 and 24 April & $4.4(0.8) b$ & $4.0(0.6) \mathrm{b}$ \\
\hline Canola oil & 24 April and 9 May & $3.6(0.9) \mathrm{b}$ & \\
\hline Pirimicarb & 9 and 24 April & $2.8(0.7) \mathrm{a}$ & $2.6(0.6) \mathrm{a}$ \\
\hline Pirimicarb & 24 April and 9 May & $2.4(0.9) \mathrm{a}$ & \\
\hline \multirow[t]{2}{*}{ Untreated } & - & $5.3(1.0) \mathrm{b}$ & $5.3(1.0) \mathrm{b}$ \\
\hline & & $\mathrm{P}<0.01$ & $\mathrm{P}<0.01$ \\
\hline
\end{tabular}

${ }^{1}$ Means followed by the same letter were not significantly different at $\mathrm{P}<0.05$.

\section{Spring trials to control BCA}

In Trial 3, when oil was applied midway through egg hatch, it was not as effective as when it was applied at the end of egg hatch (Fig. 3). The later application reduced aphid infestations $(\mathrm{P}<0.05)$ by early November (Table 3$)$.

It would appear that oil is more effective against the active stages of BCA when applied at the end of August than when it was applied to mainly eggs in mid-August. This may be due in part to the vulnerability of the newly hatched larvae that lack any protection from foliage or flowers at that time.

In Trial 4, all three treatments (canola oil: 9.6 infected tips/tree, kaolin: 5.7 tips/tree and pyrethrum: 3.0 tips/tree) that had been applied at the end of egg hatch (30 August 2000) (Fig. 3) were effective $(\mathrm{P}<0.05)$ in reducing aphid numbers at the end of October (untreated: 47.8 infected tips/tree). This trial was the first in which kaolin was effective and suggests that this product warrants further testing. Canola oil showed promise as an alternative to mineral oil for organic production. None of the treatments were fully effective and confirmed the likely need for a second treatment which could be applied earlier (autumn) or later (post-bloom).

TABLE 3: Egg hatch and number of infested tips per cherry tree after application of $2 \%$ mineral oil on two different dates during the hatch of black cherry aphid eggs on cv. Noir de Guben.

\begin{tabular}{lcc}
\hline Application date & Egg hatch $(\%)$ & No. infested tips/tree \\
\hline 13 August 1999 & 24 & $13.5 \quad(3.2) \mathrm{b}$ \\
27 August 1999 & 94 & $3.05 \quad(1.0) \mathrm{a}$ \\
Untreated & $20.8 \quad(4.5) \mathrm{b}$ \\
& $\mathrm{P}<0.01$
\end{tabular}

${ }^{1}$ Measured on 2 November 1999. Means followed by the same letter were not different at $\mathrm{P}<0.05$ 


\section{CONCLUSION}

With improved knowledge of the timing of events, autumn treatment offers a new opportunity to eliminate the need for post-bloom insecticides in the BCA control programme by reducing the number of overwintering eggs. However, to be fully effective, it will probably need to be combined with a treatment of newly hatched eggs in late August. These trials have demonstrated some useful commercial options for control of black cherry aphid in both integrated fruit production (IFP) and organic production systems. Mineral oil or pirimicarb can be used for IFP systems in autumn and/or spring, and mineral oil, canola oil or pyrethrum products for organic systems. Future work should compare the efficacy of spring versus autumn treatments and investigate the possibility of combining treatments in a programme which eliminates the need for postflowering insecticides.

\section{ACKNOWLEDGEMENTS}

This work was funded by the New Zealand Foundation for Research, Science and Technology.

\section{REFERENCES}

Blackman, R.L.; Eastop, V.F. 1985: Aphids on the world's crops. An identification guide. John Wiley \& Sons. 466 p.

Cottier, W. 1953: Aphids of New Zealand. New Zealand Department of Scientific and Industrial Research Bulletin 106.

Farrell, J.A.; Stufkens, M.W. 1988: Flight activity and weed hosts of Macrosiphoni (Homoptera:Aphididae) in Canterbury. N.Z. J. Exp. Agric. 16: 209-218.

Hintze, J.L. 1989. SOLO statistical system. BMDP Statistical Software Inc., Los Angeles, CA.

Johnson, C.G.; Taylor, L.R. 1955: The development of large suction traps for airborne insects. Ann. Appl. Biol. 43: 51-61.

Kemp, W.S. 1955: Cherry growing in Central Otago. N.Z. J. Agric. 90: 49- 60.

McLaren, G.F 1999: Pests and their management. In: McLaren, G.F.; Tate, G.F.; Wood, G.; Grandison, G.; Horner, I. Summerfruit in New Zealand. Management of pests and diseases. University of Otago Press, Dunedin, New Zealand. 136 p. 